University of San Diego

Digital USD

Spring 5-2015

\title{
Exploratory Study of Parent's Perceptions of Their Preschooler's Screen Media Usage
}

Lara Adamiak

University of San Diego

Follow this and additional works at: https://digital.sandiego.edu/honors_theses

Part of the Psychology Commons

\section{Digital USD Citation}

Adamiak, Lara, "Exploratory Study of Parent's Perceptions of Their Preschooler's Screen Media Usage" (2015). Undergraduate Honors Theses. 8.

https://digital.sandiego.edu/honors_theses/8

This Undergraduate Honors Thesis is brought to you for free and open access by the Theses and Dissertations at Digital USD. It has been accepted for inclusion in Undergraduate Honors Theses by an authorized administrator of Digital USD. For more information, please contact digital@sandiego.edu. 
Exploratory Study of Parent's Perceptions of Their Preschooler's Screen Media Usage

\author{
A Thesis \\ Presented to \\ The Faculty and the Honors Program \\ Of the University of San Diego
}

By

Lara Rogene Adamiak

Psychological Sciences

2015 


\begin{abstract}
There are conflicting research findings and evidence about the value of technology in children's development. Although the short- and long-term effects are still being investigated, the overall trend is that the contributions of technology to children's development depend on numerous factors. Among these factors are whether children's caregivers make informed choices about technology use, whether they monitor children's technology use, and whether they successfully minimize technology's overuse. Through the use of a Qualtrics survey, this study investigated parent's knowledge of the media use recommendations of the 2013 American Academy of Pediatrics Policy Statement regarding children's screen media use, parent's beliefs about the effects such screen media have on children's development, and children's use of screen media. The participants were parents of children attending a university preschool and private preschool. It was expected that parents would demonstrate little knowledge of the media use recommendations. It was also expected that parent's knowledge of the recommendations and their beliefs about the effects of screen media would predict whether they monitor their children's access to screen time. Results showed the majority of parents knew the recommendations and restricted their children's media viewing to less than the recommended amount. Some parents did not restrict their children's media viewing despite knowing the recommendations. Parent's belief of the impact of television on children's development and parent's use of television as a "babysitter" predicted the amount of television they allowed their children to watch. There is a need for continued education of parents about children's media use recommendations.
\end{abstract}

Keywords: technology, screen media, media use recommendations 
Exploratory Study of Parent's Perceptions of Their Preschooler's Electronic Usage

Media is a pervasive force that is becoming dominant in the lives of children. There are conflicting research findings and evidence about the value of media, and technology in general, for children's development. The NAEYC and the Fred Rogers Center 2012 joint position statement on technology and interactive media use with young children presents findings suggesting that technology is beneficial to children's cognitive, social, emotional, physical, and linguistic well-being as well as data showing that technology is detrimental to these aspects of children's development. This position statement indicates that technology and interactive media can promote effective learning and development when used in healthy ways by early childhood educators that still allow for the child to maintain healthy communication and social interactions with others in their life. Possible negative outcomes of technology use include sleep troubles, difficulty focusing, and delayed language development (NAEYC \& Fred Rogers Center, 2012). With such positive and negative outcomes, there is a need for caution in the use of media for children.

Product claims about the effect of technology on children's learning and development are not always accurate and as result parents should make efforts to validate claims prior to purchasing products for their children. One example of incorrect product claims are the Baby Einstein products that began being developed in 1997 and that claimed to make "baby geniuses". This series of educational videos for children that claimed to have positive outcomes on children's learning development was actually found to be doing potentially more harm than good, as they might delay children's language development (Park, 2007). Disney, who had purchased Baby Einstein from the original founders, issued a recall for the original controversial video. In 2009 they offered a full refund to those who had purchased the product between 2004 
and 2009 and also removed the product labeling that said the videos were educational (Knufken, 2009). Baby Einstein products and their claims are a good example that product claims are not always accurate and highlight the need for parents to be cautious when purchasing products based on their claims. Unfortunately, there are still product claims about educational value that are not clearly demonstrated and it appears that parents fall for these labels.

One of several studies that tested product claims was a 2010 study titled Do Babies Learn from Baby Media? (DeLoache et al., 2010). DeLoache and researchers conducted a one month long experimental study. The results showed that one year olds who watched a best-selling DVD designed and marketed for infants (12 months and up) learned significantly fewer words than infants who never watched the DVDs. Infant's highest level of learning occurred when parents taught them vocabulary words during everyday activities without using supplemental media. This study demonstrates the importance of parent-child interaction for infants' learning. A bestselling DVD marketed for vocabulary development, showed little advantage and some disadvantages over parent-child interaction for infants' learning. These results once again show that product claims are not always accurate and should be questioned.

The short- and long-term effects of media are still being investigated and need to be addressed immediately by parents, educators, researchers and health professionals (Rideout, Vandewater \& Wartella, 2003). However, the overall trend is that the contributions of technology to children's development depend on numerous factors. One such factor stated by the NAEYC and the Fred Rogers Center 2012 Position Statement relates to children's caregivers making informed choices about technology and choosing to expose their children to situations that maximize children's learning opportunities, monitoring the amount of technology use, and minimizing its misuse and overuse. The successful and developmentally appropriate 
implementation of technology in children's lives stems from caregiver's knowledge of what is recommended by professionals.

The Baby Einstein findings led to the 1999 American Academy of Pediatrics recommendation that children under two years of age should not be exposed to any television. Since then, the American Academy of Pediatrics has published other lists of established media use recommendations for parents. To investigate how accessible and useful these recommendations are, Funk, Brouwer, Curtiss and McBroom (2009) conducted a study investigating preschooler parents' knowledge of the professional recommendations for children's media use, specific screen media ratings, their beliefs about screen media effects, as well as how they actually monitor their children's media usage. Their findings indicated that parents allow their children to be exposed to more media than is recommended. Their results showed parent's knowledge of expert media usage recommendations was limited. Funk et al. concluded that parents must continue being educated about the different media guidelines as well as activities that are beneficial to children's development.

As updated media guidelines that include recommendations about newer technology (i.e. touchscreens) continue to be released by the American Academy of Pediatrics, it is useful to conduct a study of parent's current knowledge and perceptions of the impact of media devices on their children's development. The current study is a replication and expansion of the study by Funk et al. (2009) modified for 2015 by utilizing the 2013 American Academy of Pediatrics recommendations and incorporating touchscreens. Touchscreens are now more prevalent than they were in 2009, and were not included in the Funk et al. study. Unlike Funk et al.'s research, the current study also allowed for investigation of the relations between parent's knowledge, beliefs, and children's use of screen media. Through the use of a Qualtrics survey, this study 
investigated parent's knowledge of the media use recommendations of the 2013 American Academy of Pediatrics Policy Statement regarding children's screen media use, parent's beliefs about the effects such screen media have on children's development, and children's use of screen media. It was expected that parents would demonstrate little knowledge of the American Academy of Pediatrics media use recommendations for children. It was also expected that parent's knowledge of the recommendations and that their beliefs about the effects of screen media would predict whether they monitor their children's access to screen time.

\section{Method}

\section{Participants}

The participants were parents of preschool-age children at the University of San Diego's preschool (Manchester Family Child Development Center) and Saint George's Preschool in La Cañada, California. Out of 264 people who received the survey, 168 started it (64\%), and 129 completed it (49\%). Highest levels of education as reported by participants were $19.0 \%$ with Doctorate degrees, 31.0\% with Masters degrees, 42.9\% with Bachelors degrees, and 7.1\% with High School diplomas. The directors of the centers sent out the survey solicitation and consent form in their weekly news email. Parents were informed that completion of the survey was voluntary and their results would be anonymous. Participants were also informed that the purpose of the study was to learn more about children and media use and contribute to the literature on this topic.

Upon completion of the survey, the participants were offered the chance to email their name to Lara Adamiak in order to be entered into a raffle for one of two prizes, each of which was a $\$ 50$ gift card to Target. (Please see Appendix D for the email solicitation and consent form for the survey.) 


\section{Materials}

The survey included demographic questions (age, gender, education level), questions about the participant's preschool children's amount of media use, and questions about the participant's knowledge of the amount of media use that professionals recommend. The survey allowed for the investigation of parents' knowledge of the media use recommendations by the 2013 American Academy of Pediatrics Policy statement regarding children's media use, parent's beliefs of the effects that such media have on their children's development, and children's use of screen media.

Four self-report items assessed participant's preschool child's age and gender, participant's relation to child, and highest completed level of education. Nine self-report items adapted from Rideout and Hamel (2006) and Rideout et al. (2003) assessed participant's preschool-age children's amount of different types of media usage as well as parent's monitoring of such media use on a daily basis. Six self-report items adapted from Funk et al. (2009) survey questions and the American Academy of Pediatrics' Policy Statement of recommendations for children's media use assessed parent's knowledge of the professional recommendations. (Please see Appendix A for the demographic survey; Appendix B for the use survey; and Appendix C for the knowledge survey.)

\section{Procedure}

The directors of the University of San Diego's preschool (Manchester Family Child Development Center) and Saint George's Preschool in La Cañada, California, included a solicitation to participate in the survey in their weekly email. The solicitation included a link to the consent form and the Qualtrics survey. Parents could choose to complete the survey at a time convenient for them. On average, the survey took 10-15 minutes to complete. 


\section{Results}

Data was analyzed from 126 participants, including those who completed the entire survey and eliminating three participants who were considered outliers for extreme responses on certain items (i.e. reporting their child spends six hours daily on one media device). There were no significant differences in parent's responses from the two preschools. It was expected that parents would demonstrate little knowledge of the American Academy of Pediatrics media use recommendations. It was also expected that parent's knowledge of the recommendations and their beliefs about the effects of screen media would predict whether they monitor their children's access to screen time.

Unlike the findings from Funk et al. (2009) in which less than half the participants were correct in their knowledge of the screen media time recommendations from the American Academy of Pediatrics, the data from this study indicated that the majority of parents knew the recommendations. When asked, "How much time per day is recommended by professionals for a child under the age of 2 to spend on screen-based media such as TV, video games, and computers?" $76 \%$ of the participants responded correctly. When asked, "How much time per day is recommended by professionals for a child between the ages of 2 and 5 to spend on screenbased media such as TV, video games, and computers?" $93 \%$ of the participants responded correctly. The survey included an assessment of parent's knowledge of the media recommendations, including five of the actual recommendations and two items that were false recommendations. There was a tendency for participants to get the false items correct, suggesting there was no response bias in their answers. Parents appeared familiar with the recommendations to limit their children's time on screen media devices, however they appeared less familiar with 
the recommendations of having a family home use plan for all media and coviewing media (TV, movies, and videos) with their children.

Knowing the recommendations did not necessarily correspond with parents following the recommendations. Parent's knowledge of the media use recommendations for children ages 2-5 (preschoolers) and the amount of time individuals report their children spend on media devices was investigated. Results showed that $78 \%$ of parents restricted their children's screen media viewing to less than 2 hours a day, the recommended amount. However, $22 \%$ of parents did not restrict their children's screen media viewing to less than two hours. Of these parents who did not restrict their children's viewing, $85 \%$ knew the recommendation is less than two hours. Although the majority of parents knew and followed the recommendations, there is a disconnect among some parents in their knowledge of the guidelines and their actions; some parents who knew the recommendation allowed their children to use more than the daily-recommended amount of screen media time.

Parents reported data regarding media use for 66 female preschoolers and 60 male preschoolers. To analyze what media devices their preschool-age children use, parents were asked, "On average how many minutes per day does your child spend using the following?" The average across all parent's responses is that children spend 63.19 minutes watching television, 10.05 minutes on the computer, and 25.90 minutes on touchscreens. This is in comparison with parent's responses that their children spend an average of 59.90 minutes reading non-electronic books. Refer to Figure 1 for a graph of these results.

Bivariate correlations were conducted to analyze relations between parent's knowledge of recommended daily screen media time, beliefs of the educational value of television, and children's use of television screen media. Data indicated that parent's use of television as a 
distraction for children in order to provide them with time to complete tasks ("babysitting") and parent's belief of the educational value of television predicted the total amount of television children are allowed to watch. However, parent's knowledge of the media use recommendations did not predict the amount of television they allowed their children to watch. See Figure 2 for a graphic depiction and statistical significance of these results.

\section{Discussion}

The present study replicated and expanded the study by Funk et al. (2009). The survey Funk et al. used was modified for 2015 and included touchscreens in order to investigate parent's knowledge of the media use recommendations of the 2013 American Academy of Pediatrics Policy Statement regarding children's screen media use, parent's beliefs about the effects such screen media have on children's development, and children's use of screen media. It was expected that parents would demonstrate little knowledge of the American Academy of Pediatrics media use recommendations for children. It was also expected that parent's knowledge of the recommendations and their beliefs about the effects of screen media would predict whether they monitor their children's access to screen time.

Unlike the Funk et al. (2009) study, and not in support of the first expectation, the current study found that the majority of parents knew the media use recommendations. The majority of parents restricted their children's media viewing to less than the two hours recommended daily for children between ages 2-5 years of age. However, some parents did not restrict their children's screen media viewing to the recommended amount despite knowing the recommendations. Perhaps, even if parents know the guidelines, it is possible that they are uncertain about the importance of why the guidelines exist. 
Children are spending more time watching television than they are using computers or touchscreens. As demonstrated by Do Babies Learn from Baby Media? (DeLoache et al., 2010), parent-child interaction is beneficial for children's learning. Preschoolers are likely to be receiving assistance from someone else when reading books, as their literacy skills are still developing. The fact that parents report their preschool-age children spend almost as much time reading non-electronic books as watching television on a daily basis is suggested to have beneficial impacts on children's learning. Parent's belief of the impact of television on children's development and parent's use of television as a "babysitter" for their children when they need time to themselves to complete tasks predicted the total amount of television they allowed their children to watch.

This study is beneficial in suggesting whether the professional media use recommendations are being taken seriously and impacting how parents monitor their children's use of media devices. As updated media recommendations continue to be released by the American Academy of Pediatrics, it is useful to conduct a study of parent's current knowledge and perceptions of the impact of media on their children's development. Despite the majority of parents knowing the recommendations, it appears that some individuals do not adhere to them and allow their children to use more than the recommended amount of screen media time.

This study is exploratory and mainly descriptive, and therefore no causal conclusions can be drawn. The parents who participated in this study are educated parents of preschool-age children; perhaps parent's knowledge would be different in a less educated group of participants. Children's amount of time on screen media devices may differ if they were of a different age group (i.e. teenagers). This study included a self-report survey in which participants answered questions anonymously through an online survey. It is possible that parents responded according 
to what they feel is acceptable by society (social desirability bias) and children are not really doing what their parents are reporting.

These findings provide a foundation for future studies. It would be advantageous to conduct a study with a focus group, so that individual's reasoning of why they allow their children to use certain devices and how much media time they allow their children could be investigated by researchers. The sample size and demographic of future studies should be expanded beyond educated parents of preschool-age children in Southern California preschools to allow for the results to be generalized to a larger population. This study determined predictors of television screen media time, however future studies should determine predictors of computer screen media time and touchscreen screen media time. As touchscreens are a newer technology, more information on children's use of touchscreens and the impact of touchscreens on children's development is necessary.

Media is a pervasive force that is becoming more dominant in the lives of children. It can be quite simple for parents to hand their children media devices as a method of "babysitting" their children. Children often are fascinated by and enjoy playing with media devices. However, there are conflicting research findings and evidence about the value of technology in children's development. Product claims have shown to not always be empirically supported. The American Academy of Pediatrics recommends that parents take caution by following the media use recommendations when allowing their children screen time. Parents are encouraged to take an active role in educating themselves about the professional media recommendations that exist and in monitoring the amount and content of media their children are exposed to. 


\section{Acknowledgements}

Thank you to Dr. Patricia Kowalski who served as my Thesis Advisor. She assisted with developing the research topic, constructing the survey, analyzing the data, and editing the research report. I greatly appreciate the learning opportunities she provided and the many hours she contributed to my research and thesis paper.

I would like to thank the University of San Diego's preschool (Manchester Family Child Development Center) and Saint George's Preschool in La Cañada, California for allowing me to distribute surveys and collect data from these sites. Completion of this research could not have been accomplished without the support of these preschools.

Thank you to the University of San Diego's Hinman Grant which provided funding for my research. 


\section{References}

American Academy of Pediatrics. (2013). Policy statement: Children, adolescents, and the media. Pediatrics, 132(5), 958-961. doi: 10.1542/peds.2013-2656

DeLoache, J., Chiong, C., Sherman, K., Islam, N., Vanderborght, M., Troseth, G., ... O'Doherty, K. (2010). Do Babies Learn From Baby Media? Psychological Science, 21(11), 15701574. doi:10.1177/0956797610384145

Funk, J., Brouwer, J., Curtiss, K., \& McBroom, E. (2009). Parents of preschoolers: Expert media recommendations and ratings knowledge, media-effects beliefs, and monitoring practices. Pediatrics, 123(3), 981-988.

Knufken, D. (2009). After controversy, Disney issues Baby Einstein recall. Retrieved February 11, 2015, from, http://www.businesspundit.com/after-controversy-dinsey-issues-babyeinstein-recall/

McManis, L.D., \& Gennewig, S.B. (2012). Finding the education in educational technology learners. Young Children, 67, 14-24.

NAEYC \& Fred Rogers Center for Early Learning and Children's Media. (2012). Technology and Interactive Media as Tools in Early Childhood Programs Serving Children from Birth through Age 8. Joint position statement. Washington, DC: NAEYC; Latrobe, PA: Fred Rogers Center for Early Learning at Saint Vincent College. www.naeyc.org/files/naeyc/file/positions/PS_technology_WEB2.pdf.

Neumann, M.M., \& Neumann, D.L. (2014). Touch screen tablets and emergent literacy. Early Childhood Education Journal, 42(4), 231-239.

Park, A. (2007, August). Baby Einstein: Not so smart after all. Time. Retrieved from http://content.time.com/time/health/article/0,8599,1650352,00.html 
Rideout, V.J., \& Hamel, E. (2006). The media family: Electronic media in the lives of infants, toddlers, preschoolers and their parents. Menlo Park, CA: Kaiser Family Foundation. Rideout, V.J., Vandewater, E.A., \& Wartella, E.A. (2003). The media family: Zero to six: Electronic media in the lives of infants, toddlers, and preschoolers. Menlo Park, CA: Kaiser Family Foundation. 


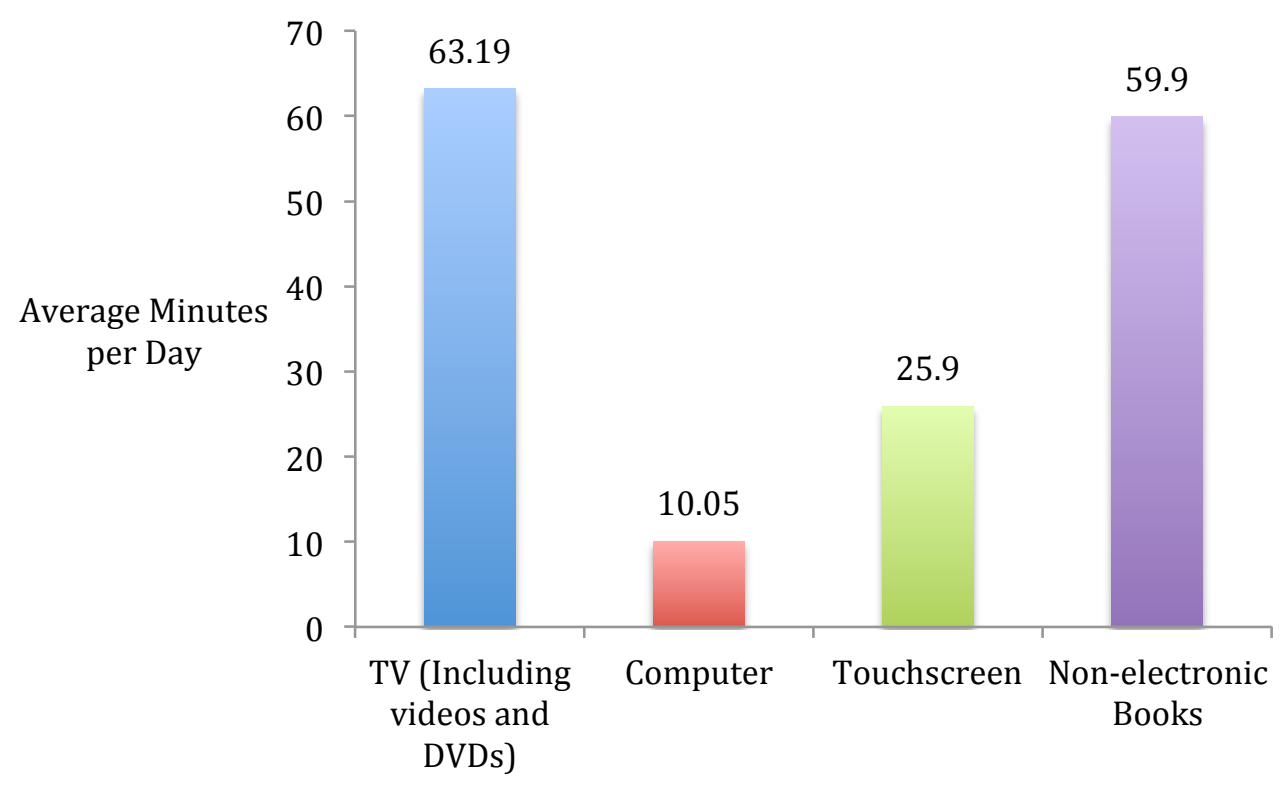

Figure 1. Preschool-age children's average daily use of screen media devices and books as reported by parents. 


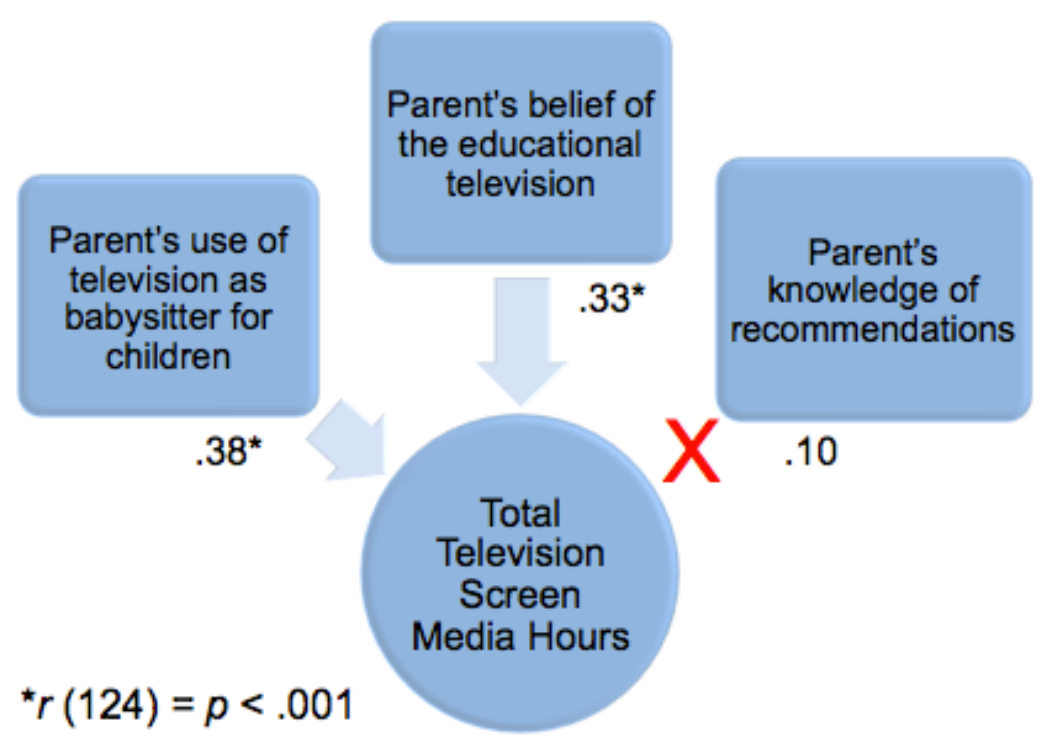

Figure 2. Flow chart indicating that parent's use of television as a distraction for children in order to provide time for them to complete tasks ("babysitting") and parent's belief of the educational value of television predict the total amount of television parents allow their children to watch. 


\section{APPENDIX A:}

Demographic Survey

1. How old is your preschool-age child? years old

2. What is your preschool-age child's gender? F M

3. How are you related to the child? Child's mother

Child's father

Other:

4. What is your highest completed level of education?

High school graduate

Bachelors

Masters

Doctorate 


\section{APPENDIX B:}

Use Survey

1.On average, how many hours per day does your child spend using the following?

Television (including videos and DVDs: hours

Computer: hours

Touchscreens: hours

Reading or being read to (non-electronic books): hours

2. What are your child's favorite television programs (including videos and DVDs)?

3. What are your child's favorite computer programs?

4. What are your child's favorite touchscreen programs/applications/E-books?

5. What are your child's favorite non-electronic books?

6. If your child uses any of these mediums, in a typical day how often do you use it with them? Television (including videos and DVDs)
a. All the time
b. Most of the time
c. About half the time
d. Less than half the time
e. None of the time

\section{Computer}
a. All the time
b. Most of the time
c. About half the time
d. Less than half the time
e. None of the time

\section{Touchscreen}
a. All the time
b. Most of the time
c. About half the time
d. Less than half the time
e. None of the time

Non-electronic Books
a. All the time
b. Most of the time
c. About half the time
d. Less than half the time
e. None of the time 
7. Do you have any rules about the following?
a. What your child can/can't watch on TV
Yes No N/A
b. How much time your child can spend watching TV
Yes No N/A
c. What your child can/can't do on the computer
Yes No N/A
d. How much time your child can spend on the computer
Yes No N/A
e. What your child can/can't do on the touchscreen
Yes No N/A
f. How much time your child can spend on the touchscreen
Yes No N/A

8. How often is the television on as background noise in your house?
a. Never
b. Sometimes
c. Most of the time
d. Always

9. How likely are you to place your child in front of the television when you need time to yourself to complete a task?
a. Very unlikely
b. Unlikely
c. Somewhat unlikely
d. Somewhat likely
e. Likely
f. Very likely 


\section{APPENDIX C:}

Knowledge Survey

1. Does the American Academy of Pediatrics have recommendations for children's media use?

Yes No Unsure

2. How much time per day is recommended by professionals for a child under the age of 2 to spend on screen-based media such as TV, video games, and computer?

a. No time at all

b. Less than 2 hours

c. Between 2-5 hours

d. Unsure

3. How much time per day is recommended by professionals for a child between the ages of 2 and 5 to spend on screen-based media such as TV, video games, and computer?
a. No time at all
b. Less than 2 hours
c. Between 2-5 hours
d. Unsure

4. What media guidelines are recommended by the American Academy of Pediatrics? Please check all that you feel are recommended.

Coview TV, movies, and videos with children and teenagers, and use this as a way of discussing important family values

Limit the amount of total screen time to $<1$ to 2 hours per day

Expose children to cartoons rather than live action television programs

Monitor what media your children are accessing, including any web sites they are visiting and social media sites they may be using

Discourage screen media exposure for children $<2$ years of age

Keep the TV set and Internet connected electronic devices out of the child's bedroom

Model active parenting by establishing a family home use plan for all media. As part of the plan, enforce a mealtime and bedtime "curfew" for media devices, including cell phones

Establish reasonable but firm rules about cell phones, texting, Internet, and social media use Limit media exposure to 20-minute at a time

5. In general, what impact do the following have on children's learning?

Television (including videos and DVDs):
a. Mostly hurts
b. Somewhat hurts
c. No effect
d. Somewhat helps
e. Mostly helps 
Computer:
a. Mostly hurts
b. Somewhat hurts
c. No effect
d. Somewhat helps
e. Mostly helps

Touchscreen:

a. Mostly hurts

b. Somewhat hurts

c. No effect

d. Somewhat helps

e. Mostly helps

6. Please tell me how important, if at all, you think each of the following is for the intellectual development of children.

Reading books:
a. Unsure
b. Not at all important
c. Not too important
d. Somewhat important
e. Very important

\section{Watching "Sesame Street":}
a. Unsure
b. Not at all important
c. Not too important
d. Somewhat important
e. Very important

Watching other educational TV programs:
a. Unsure
b. Not at all important
c. Not too important
d. Somewhat important
e. Very important

Watching educational videos or DVDs:
a. Unsure
b. Not at all important
c. Not too important
d. Somewhat important
e. Very important

Playing educational computer games: 

a. Unsure
b. Not at all important
c. Not too important
d. Somewhat important
e. Very important

Using educational touchscreen applications:
a. Unsure
b. Not at all important
c. Not too important
d. Somewhat important
e. Very important 


\section{APPENDIX D: \\ Email Solicitation and Consent Form for Survey}

Hello,

My name is Lara Adamiak. I am a student in the Department of Psychological Sciences at the University of San Diego, San Diego, CA. I am conducting a research study for my Honors Senior Thesis project about parent's perceptions of children's media use and I would like to invite you to participate.

The purpose of this study is to learn more about children and media use and contribute to the literature on this topic.

If you decide to participate, you will be asked to complete an online survey. The survey will take less than 15 minutes to complete. The questions relate to your children's media use as well as your perceptions of children's media use. You will also be asked a couple questions about yourself, such as your gender and level of education.

Participants will have the opportunity to be entered into a raffle for two prizes, each of which are a \$50 gift card to Target. If you wish to be entered into this raffle, upon completing the survey please respond to my email with your name so that I can enter you into the drawing. Also, in your email, please indicate if you are interested in the findings of my Honors Thesis Project.

The risks of participating in this study are minimal and no more than those encountered in everyday life. All questions will be answered anonymously, as you will not provide any source of identification in the survey. Although aggregate results might be made public, all individual responses will remain confidential to you only. We will keep the study data for a minimum of 5 years.

Taking part in this study is entirely optional. Choosing not to participate will have no effect on any other services to which you are entitled. You may quit being in the study at any time or decide not to answer any specific questions. Should you decide to participate, please print out a copy of this page for future reference.

I will be happy to answer any questions you have about the study. You may contact me at (818) 590-4577 or (ladamiak@sandiego.edu). You can also contact my advisor, Dr. Patricia Kowalski, at (619) 260-4003 or (kowalski@sandiego.edu).

If you would like to participate, please click on this link to begin the study: http://

Thank you for your consideration.

Lara Adamiak

ladamiak@sandiego.edu 